\title{
STOMATOCYST 29 CABAŁA IS A POLLEN GRAIN, NOT A CHRYSOPHYTE CYST
}

\author{
JOLANTA PIĄTEK \\ Department of Phycology \\ W. Szafer Institute of Botany, Polish Academy of Sciences \\ Lubicz 46, 31-512 Kraków, Poland \\ e-mail: cabala@ib-pan.krakow.pl \\ (Received: October 5, 2007. Accepted: November 8, 2007)
}

\begin{abstract}
Stomatocyst 29 Cabała was described from the Żabie Oko lake in the Tatra Mts, Poland, in 2005 as a chrysophycean stomatocyst new to science. The examination of the recently found specimens in the Dwoisty Staw Gąsienicowy lake in the Tatra Mts, including their chemical composition, showed that stomatocyst 29 is not a cyst, but a pollen grain.
\end{abstract}

KEY WORDS: Chrysophyte stomatocyst, pollen, energy dispersive spectrometer (EDS).

\section{INTRODUCTION}

While investigating the taxonomy of chrysophyte stomatocysts occurring in the Dwoisty Staw Gąsienicowy lake in Tatra Mts, Poland, I encountered several specimens of one morphotype that were morphologically similar to stomatocyst 29 Cabała J. 2005. The stomatocyst was described from the Żabie Oko lake in the Tatra Mts as new to science two years ago (Cabała 2005) and was later found in the material from the Czarny Staw Gasienicowy lake in the Tatra Mts (Piątek 2006). A comparative study of stomatocyst 29 and the specimens found in the Dwoisty Staw Gąsienicowy lake showed that this morphotype is actually a pollen grain and not a chrysophyte stomatocyst. This conclusion is also supported by the examination of the chemical components of the false stomatocyst 29 Cabała J. 2005 and the true stomatocyst 311 Pla 2001 using EDS.

\section{MATERIAL AND METHODS}

The material was collected at the shore of the Dwoisty Staw Gąsienicowy lake, in the Tatra Mts, Poland, on 22 September 2005, from: (i) surface water with subsurface water and (ii) bottom sediment. Ten samples were taken from the lake. A detailed characterization of the lake and the identified stomatocysts will be presented in a separate paper.

In the laboratory each sample was placed in a glass scintillation vial, covered with $10 \% \mathrm{HCl}$ (to remove carbonates) and allowed to stand for $24 \mathrm{~h}$, boiled for $15 \mathrm{~min}$, and rinsed several times with distilled water. Then, the samples were covered with $30 \% \mathrm{H}_{2} \mathrm{O}_{2}$ and also allowed to stand for $24 \mathrm{~h}$, then boiled for $30 \mathrm{~min}$ with a small amount of $\mathrm{KClO}_{3}$, and rinsed several times with distilled water, with a settling time of $24 \mathrm{~h}$ between each aspiration. Finally, the samples were slurried in glass vials and covered with $95 \%$ ethanol. The prepared material was used for scanning electron microscope (SEM) and energy dispersive spectrometer (EDS) analysis. For these studies, a small aliquot of each slurry was pipetted onto clean glass, air-dried, and affixed to an aluminium stub with a double-sided transparent tape. The stubs were sputter-coated with carbon using a CRESSINGTON sputter-coater and viewed with a Hitachi S-4700 scanning electron microscope and a NORAN Vantage energy dispersive spectrometer.

SEM and EDS analyses were conducted at the Laboratory of Field Emission Scanning Electron Microscopy and Microanalysis at the Institute of Geological Sciences of the Jagiellonian University, Kraków, Poland.

\section{RESULTS AND DISCUSSION}

Cabała (2005) described stomatocyst 29 as new to science based on a specimen found in the water squeezed from plants in the Żabie Oko lake in the Tatra Mts, Poland. The specimen was irregular but slightly pyramidal in shape, $13.8 \mu \mathrm{m}$ in diameter. The pore was regular to slightly concave, $1.1 \mu \mathrm{m}$ in diameter, the collar was conical with a rounded apex and a sloping inner margin, $3.3 \mu \mathrm{m}$ in diameter and $0.8 \mu \mathrm{m}$ in height. The cyst body was ornamented with 

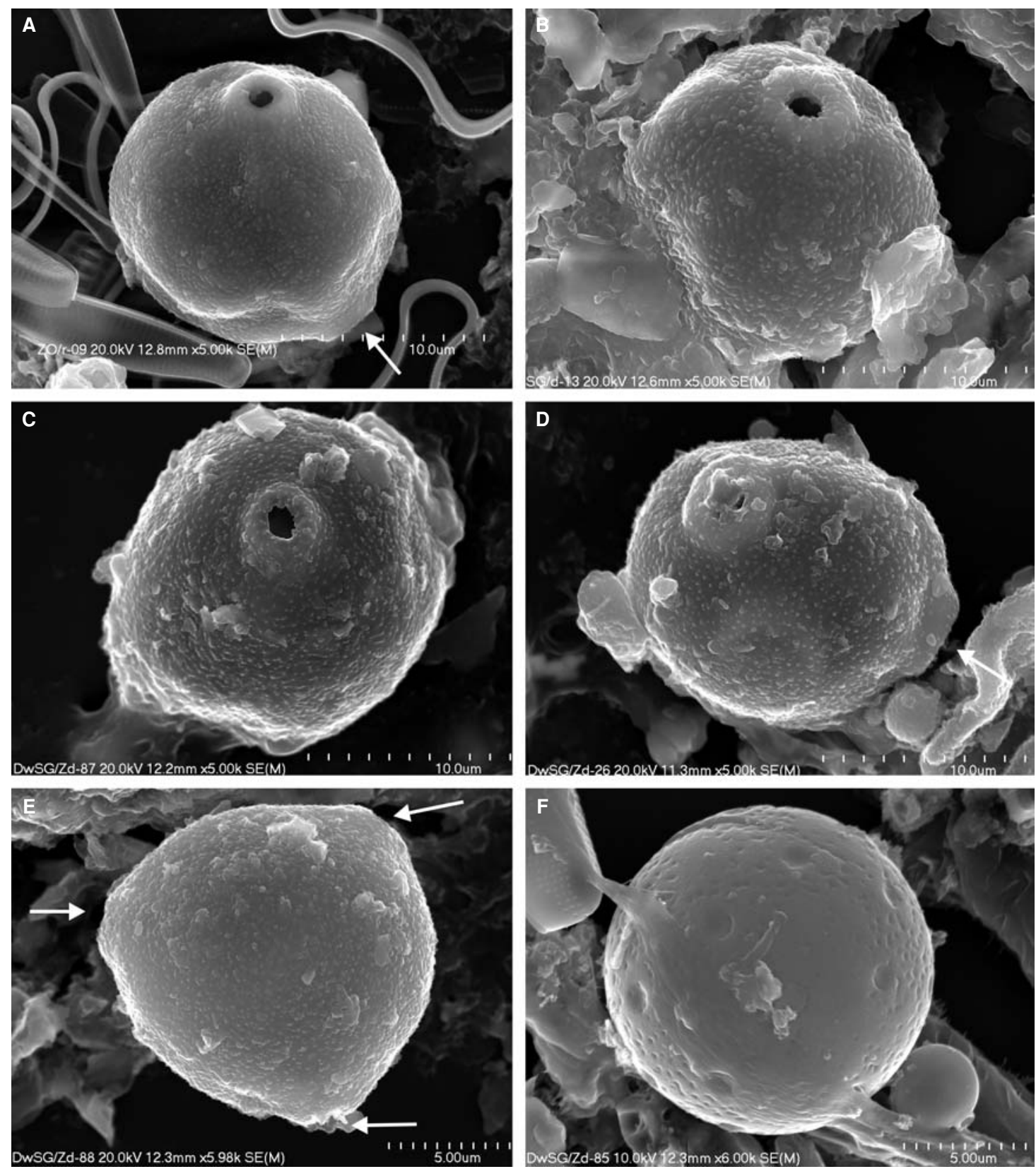

Fig 1. A: Stomatocyst 29 Cabała J. = pollen grain of Betula sp. from the Żabie Oko lake; B: Stomatocyst 29 Cabała J. = pollen grain of Betula sp. from the Czarny Staw Gąsienicowy lake; C-D: Pollen grain of Betula sp.; E: Pollen grain of Corylus avellana; F: Stomatocyst 311 Pla 2001.

scabrae, 0.1-0.2 $\mu \mathrm{m}$ in diameter, which covered the entire cyst body, including the outer collar margin. Figure 1A shows the iconotype of stomatocyst 29. Stomatocyst 29 was later found in the material collected in the Czarny Staw Gasienicowy lake, also in the Polish part of the Tatra Mts (Piątek 2006). Its morphological characters were almost the same as those of the specimen from the Zabie Oko lake. The specimen was irregular but slightly pyramidal in shape, with a regular pore, $1.6 \mu \mathrm{m}$ in diameter. The collar was conical with a rounded apex and a sloping inner margin, $4.9 \mu \mathrm{m}$ in diameter and $0.7 \mu \mathrm{m}$ high. The cyst body was ornamented with scabrae, 0.1-0.2 $\mu \mathrm{m}$ in diameter, that covered the entire cyst body, including the outer collar margin and was larger in size $(15.1 \mu \mathrm{m}$ in diameter) than that of the specimen from the type locality. Figure 1B shows a micrograph of stomatocyst 29 from the Czarny Staw Gąsienicowy lake. In both lakes, stomatocyst 29 occurred singly, and its morphology was described on the basis of only one specimen in each case. In both specimens only one collar and pore were clearly seen, although another collar, not visible clearly, can possibly be discerned in the specimen from the type locality (Fig. 1A, indicated by arrow). The presence of the collar is more evident in the light of the present data (see below).

Specimens resembling stomatocyst 29 occurred more abundantly in the material collected in the Dwoisty Staw Gąsienicowy lake. They differed, however, from the previously found specimens by having 2-3 collars and pores (Fig. 1C-E). Therefore, it seemed justified to suppose that they might represent not a chrysophyte cyst but small pollen grains. I analyzed the chemical components of the specimens resembling stomatocyst 29 , specimens of the pollen grain and specimens of the typical chrysophyte stomatocyst (stomatocyst $311 \mathrm{Pla} 2001$ ) with the help of the energy dispersive spectrometer (EDS) system. The chemical composition of the specimens resembling stomatocyst 29 (Fig. 


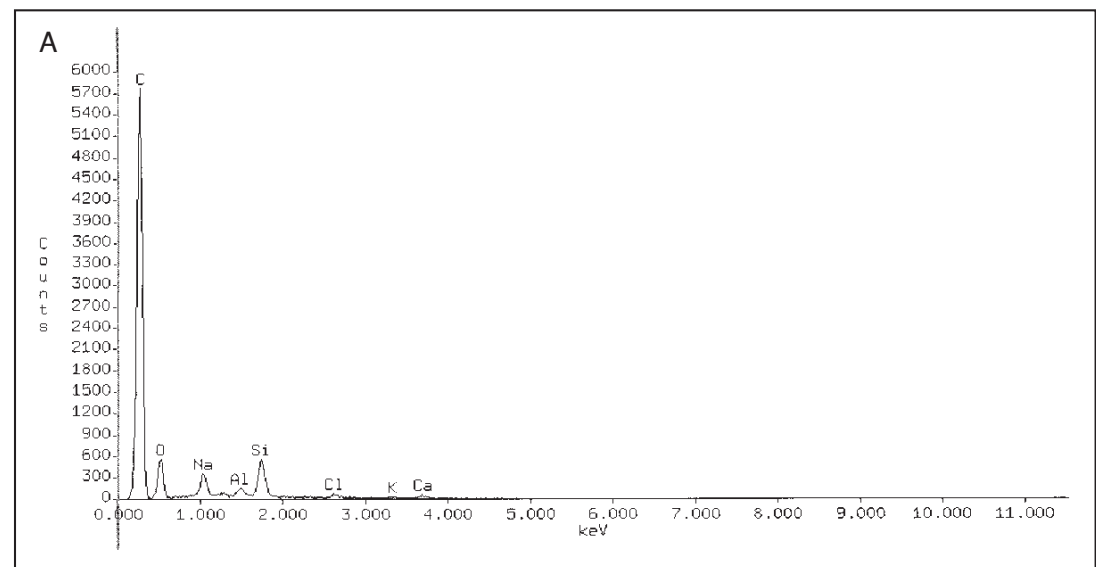

DwSG-Zd-87

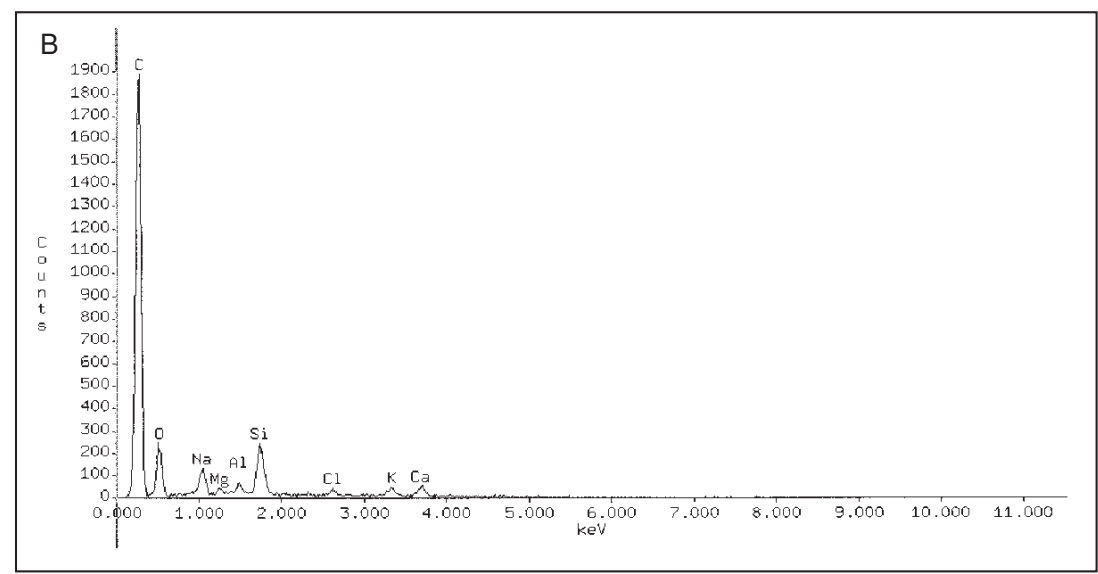

DwSG-Zd-88

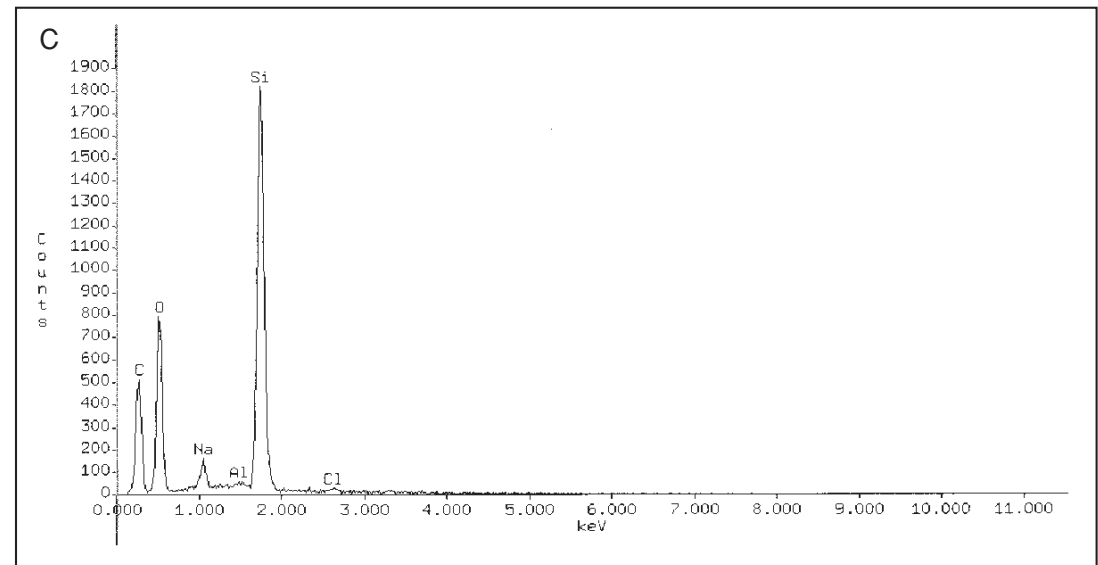

DwSG-Zd-85
Fig 2. A: Chemical composition (EDS) of pollen grain of Betula sp.; B: Chemical composition (EDS) of pollen grain of Corylus avellana; C: Chemical composition (EDS) of stomatocyst 311 Pla 2001.
1C, and equivalent chemical composition presented in Fig. 2A) and the pollen grain (Fig. 1E, and equivalent chemical composition presented in Fig. 2B) differed completely from that of the specimens of typical chrysophyte stomatocyst $311 \mathrm{Pla} 2001$ (Fig. 1F, and equivalent chemical composition presented in Fig. 2C). As is clearly visible in the diagrams, silica $(\mathrm{Si})$ and oxygen $(\mathrm{O})$ are the main components of the chrysophyte stomatocyst. The relatively high concentration of carbon (C) is caused by the fact that the SEM samples were carbon-coated. However, the concentration of carbon in this sample is much lower than that in the specimens representing ,stomatocyst 29" and the pollen grain. The identification of these latter specimens revealed that they are similar to pollens of Betula sp. (Figs 1C-D) and Corylus avellana (Fig. 1E). The specimens similar to pollens of Betula sp. were triangular in side view (16.0 $\mu \mathrm{m}$ in diameter), had a well-ringed and shouldered pore, $1.3 \mu \mathrm{m}$ in diameter, and the surface ornamented with scabrae, $0.2 \mu \mathrm{m}$ in diameter. They were twice as small as typical pollen grains of Betula sp. (they are usually 28-33 $\mu \mathrm{m}$ in diameter); this, however, may be an artefact caused by the chemical treatment of the SEM samples. The specimens identified as pollen grains of Corylus avellana were sub-triangular in polar view and sub-oblate in equatorial view, $13.8 \mu \mathrm{m}$ in diameter, had three pores, and the surface was ornamented with small scabrae, $0.2 \mu \mathrm{m}$ in diameter. They were also twice as small as typical pollen grains of Corylus avellana. 
The specimen used for description of stomatocyst 29 (Cabała 2005) is also a pollen grain, but cannot be identified even at the genus level. The same regards the specimen reported as stomatocyst 29 from the samples collected in the Czarny Staw Gąsienicowy lake (Piątek 2006).

Stomatocyst samples used for SEM studies were prepared in the same way in all the cases. They were treated with various strong chemicals to remove organic matter. The same applies to the study in which stomatocyst 29 was described as new to science (Cabała 2005). Therefore, I did not suppose that the samples prepared in this way could contain any organic forms besides diatoms and stomatocysts (forms constructed with silica). During the present work I found information that pollen grains are composed of sporopolenin, an organic chemical component that is resistant to numerous chemical factors, including organic and non-organic acids. For this reason pollen grains are very difficult to destroy, and can remain even in the fossil stage (G. Worobiec, pers. comm.). Moreover, the sizes and ornamentation of pollen grains of cf. Betula sp. and cf. Corylus avellana were very similar to typical chrysophyte stomatocysts.

In conclusion, the description of stomatocyst 29 Cabała J. 2005 as a chrysophyte cyst is erroneous. Any findings reported as this stomatocyst (Cabała 2005; Piątek 2006) as well as stomatocyst 29 Cabała J. 2005 itself must be ignored.

\section{ACKNOWLEDGEMENTS}

I am grateful to Prof. Konrad Wołowski (Kraków) for his valuable advice, to Dr. Marcin Piątek (Kraków) and Dr. Joanna Kazik (Łódź) for their useful remarks on the manuscript and the help with the English, to Dr. Agnieszka Wacnik (Kraków) for her help with the identification of pollen grains, and to Anna Łatkiewicz (Kraków) for her assistance with SEM pictures and EDS analysis. This study was supported by the Polish Ministry of Science and Higher Education for the years 2005-2008, grant no. 2 P04G 02328.

\section{LITERATURE CITED}

CABAŁA J. 2005. Chrysophycean stomatocysts from Morskie Oko and Żabie Oko lakes in the Tatra National Park, Poland. Acta Soc. Bot. Pol. 74: 504-514.

PIĄTEK J. 2006. Stomatocysts of the Dolina Gąsienicowa valley in the Tatra Mts. 1. Czarny Staw Gąsienicowy and Zmarzły Staw Gąsienicowy lakes. Pol. Bot. J. 51: 61-77.

PLA S. 2001. Chrysophycean cysts from the Pyrenees. Biblioth. Phycol. 109: 1-179. 